\title{
OPEN Probing rapid carbon fixation in fast-growing seaweed Ulva meridionalis using stable isotope ${ }^{13} \mathrm{C}$-labelling
}

\begin{abstract}
Shuntaro Tsubaki ${ }^{1 \bowtie}$, Hiroshi Nishimura ${ }^{2}$, Tomoya Imai ${ }^{2}$, Ayumu Onda ${ }^{3}$ \& Masanori Hiraoka ${ }^{4}$
The high growth rate of Ulva seaweeds makes it a potential algal biomass resource. In particular, Ulva meridionalis grows up to fourfold a day. Here, we demonstrated strong carbon fixation by $U$. meridionalis using ${ }^{13} \mathrm{C}$ stable isotope labelling and traced the ${ }^{13} \mathrm{C}$ flux through sugar metabolites with isotope-ratio mass spectrometry (IR-MS), Fourier transform ion cyclotron resonance mass spectrometry (FT-ICR-MS), ${ }^{13} \mathrm{C}$-nuclear magnetic resonance spectrometry $\left({ }^{13} \mathrm{C}-\mathrm{NMR}\right)$, and gas chromatography-mass spectrometry (GC-MS). U. meridionalis was first cultured in ${ }^{13} \mathrm{C}$-labelled enriched artificial seawater for $0-12 \mathrm{~h}$, and the algae were collected every $4 \mathrm{~h}$. $U$. meridionalis grew 1.8 -fold (dry weight), and the ${ }^{13} \mathrm{C}$ ratio reached $40 \%$ in $12 \mathrm{~h}$, whereas ${ }^{13} \mathrm{C}$ incorporation hardly occurred under darkness. At the beginning of the light period, ${ }^{13} \mathrm{C}$ was incorporated into nucleic diphosphate (NDP) sugars in $4 \mathrm{~h}$, and ${ }^{13} \mathrm{C}$ labelled peaks were identified using FT-ICR-MS spectra. Using semiquantitative ${ }^{13} \mathrm{C}$-NMR measurements and GC-MS, ${ }^{13} \mathrm{C}$ was detected in starch and matrix polysaccharides after the formation of NDP sugars. Moreover, the 14:10 light:dark regime resulted into $85 \%$ of ${ }^{13} \mathrm{C}$ labelling was achieved after $72 \mathrm{~h}$ of cultivation. The rapid ${ }^{13} \mathrm{C}$ uptake by $\mathrm{U}$. meridionalis shows its strong carbon fixation capacity as a promising seaweed biomass feedstock.
\end{abstract}

Green tides of Ulva seaweeds are increasing with the eutrophication of the sea and have become a major environmental problem ${ }^{1}$. Rapid and vast Ulva growth disturbs the ecological system at the seashore. The growth dynamics and mechanisms of fast growth in Ulva have been studied to mitigate Ulva green tides ${ }^{2-4}$. At the same time, Ulva is an expected biomass source that can capture $\mathrm{CO}_{2}$ and convert it into renewable biochemicals ${ }^{5}$. Filamentous Ulva meridionalis is a potential seaweed species that exhibits the fastest growth rate ever found in multicellular autotrophic plants ${ }^{6,7}$. U. prolifera, one of the most widely known edible Ulva species, doubles in a day at the optimised culturing conditions; in contrast, U. meridionalis grows over fourfold in a day. In general, many Ulva grow from winter to spring, whereas U. meridionalis grows in summer. U. meridionalis has a high rate of photosynthetic carbon fixation, a high frequency of cell proliferation, and rapid formation of algae bodies consisting of cell walls in high-temperature environments. The accumulated cell and cell wall components are important biochemical resources that include polysaccharides and rare sugars ${ }^{5}$, which are produced by Ulva through extraction and hydrolysis processes ${ }^{8-10}$. Land cultivation of Ulva has been extensively studied for stable seaweed production for both food and biomass applications ${ }^{11}$. The "germling cluster method" allows mass production of Ulva by clustering the algae bodies and cultivating them in high density floating Ulva clusters in a land tank. This method provides efficient exposure for Ulva growth by three-dimensionally stirring the clusters. Ulva are easily collected by a coarse filtration, which is much easier than harvesting microalgae biomass that requires flocculation and centrifugation. This efficient cultivation system enhances Ulva growth and captures more $\mathrm{CO}_{2}$.

Ulva suffers various environmental stresses such as frequent submergence into seawater and exposure to air by tides, high light intensity, and dryness at the intertidal zone. However, their photosynthetic systems are highly adapted to severe environments ${ }^{12}$. At the same time, Ulva are widely distributed worldwide and are a model macroalgae that are used for studying photosynthesis mechanisms ${ }^{13}$. Most macroalgae utilise bicarbonate ions $\left(\mathrm{HCO}_{3}^{-}\right)$as a carbon source because it is a major species of $\mathrm{CO}_{2}$ that occurs at the $\mathrm{pH}$ and salt concentration

\footnotetext{
${ }^{1}$ School of Materials and Chemical Technology, Tokyo Institute of Technology, E4-3, 2-12-1, Ookayama, Meguro-ku, Tokyo 152-8552, Japan. 'Research Institute for Sustainable Humanosphere, Kyoto University, Gokasho, Uji 611-0011, Japan. ${ }^{3}$ Research Laboratory of Hydrothermal Chemistry, Faculty of Science, Kochi University, 2-17-47 Asakurahonmachi, Kochi 780-8073, Japan. ${ }^{4}$ Usa Marine Biological Institute, Kochi University, Inoshiri, Usa, Tosa, Kochi 781-1164, Japan. ${ }^{\boxplus}$ email: shuntaro.tsubaki@gmail.com
} 
levels of seawater ${ }^{14}$. Carbonic anhydrase shifts the equilibrium of $\mathrm{HCO}_{3}{ }^{-}$and $\mathrm{CO}_{2}$ to enhance $\mathrm{CO}_{2}$ uptake $\mathrm{u}^{15}$. Several macroalgae, including Ulva, have a proton pump system that enhances the $\mathrm{HCO}_{3}{ }^{-}$uptake. Moreover, Ulva is equipped with a carbon concentrating mechanism (CCM). Beer et al. reported that the introduction of ${ }^{14} \mathrm{C}$ pulses into $U$. fasciata under light immediately produces ${ }^{14} \mathrm{C}$ labelled glycerate 3 -phosphate with more than $90 \%$ of molecules labelled, and it was further transferred to other photosynthesis products such as sugars ${ }^{16}$. Since photorespiration is suppressed in Ulva, they concluded that Ulva have a carbon concentrating system in their chloroplasts along with their efficient $\mathrm{HCO}_{3}{ }^{-}$uptake mechanism ${ }^{17,18}$. The CCM maintains the $\mathrm{CO}_{2}$ in cells at a sufficiently high level to saturate carboxylation by Rubisco in the Calvin cycle ${ }^{17}$. The CCM was also found in U. prolifera, which caused huge green tides in the Yellow Sea ${ }^{19}$. Ulva also exhibits high tolerance to strong light by non-photochemical quenching. Efficient photosynthesis can be maintained under strong light by protecting photosystems I and II from excess electrons $\left(\mathrm{e}^{-}\right)$by trapping them in xanthophyll ${ }^{20,21}$.

Various polysaccharides such as storage, cell wall, and matrix polysaccharides are formed through biosynthetic pathways after carbon fixation in the Calvin cycle. Ulva bodies consist of cellulose $(\sim 10 \%)$, matrix polysaccharides $(\sim 30 \%)$, and starch $(\sim 10 \%)$ along with proteins $(\sim 20 \%)^{8}$. Ulva seaweeds are characterised by matrix polysaccharides (ulvan) that are heteropolysaccharides consisting of rhamnose (Rha), glucuronic acid (GlcA), iduronic acid (IdoA), and sulfates ${ }^{22-24}$. In some cases, mannose (Man), galactose (Gal), and arabinose (Ara) are found in ulvan. Various fine structures were reported including: (1) Type-A ulvanbiouronic 3-sulfate $\left(A_{3 S}\right)$, $\beta$-D-GlcA $(1 \rightarrow 4)$-L-Rha $3 S \rightarrow 4) \beta$-D-GlcA $(1 \rightarrow 4)$ - $\alpha$-L-Rha 3S $\left(1 \rightarrow ;(2)\right.$ Type B ulvanbiouronic 3-sulfate $\left(B_{3 S}\right)$, $\alpha$-L-IdoA $(1 \rightarrow 4) \alpha$-L-Rha $3 S \rightarrow 4) \alpha$-L-IdoA $(1 \rightarrow 4)$ - $\alpha$-L-Rha $3 S\left(1 \rightarrow\right.$; (3) ulvanbiose 3 -sulfate $\left.\left(\mathrm{U}_{3 S}\right), \rightarrow 4\right) \beta$-DXyl $(1 \rightarrow 4) \alpha$-L-Rha $3 S\left(1 \rightarrow\right.$; (4) ulvanobiose $2^{\prime}, 3$-disulfate $\left.\left(\mathrm{U}_{2 \mathrm{~s}, 3 \mathrm{~s}}{ }^{\prime}\right), \rightarrow 4\right) \beta$-D-Xyl $2 \mathrm{~S}(1 \rightarrow 4) \alpha$-L-Rha $3 \mathrm{~S}\left(1 \rightarrow \rightarrow^{23,24}\right.$. Biosynthesis of ulvan occurs from nucleic diphosphate (NDP) sugar, similar to pectin biosynthesis in higher plants $^{23}$. D-fructose-6-P supplied from photosynthesis and glucogenesis is converted to uridine diphosphate glucose (UDP-Glc) through several steps. The corresponding NDP sugars to each monosaccharide are produced through the interconversion of UDP-Glc. For instance, UDP-GlcA is converted from UDP-Glc or inositol and further converts to UDP-Xyl. Rha originates from UDP-L-Rha or dTDP-L-Rha, which are converted from UDPGlc. Ulvan is synthesised by glycosyltransferase from the above-mentioned NDP sugars in the Golgi apparatus. Polysaccharides are then transported to the apoplast, and further assembling and modifications occur. However, the biosynthetic pathway of ulvan is yet not well understood although it is involved in the rapid growth of Ulva.

Isotope labelling has been used to analyse the kinetics of carbon uptake by photosynthesis and its transfer into metabolites. Percival et al. used the radioisotope ${ }^{14} \mathrm{C}$ to study carbon fixation of $U$. lactuca and its transfer into sugar metabolites ${ }^{25}$. They reported that ${ }^{14} \mathrm{C}$ incorporation in $80 \%$ aqueous ethanol extract or hot water extract was detected after culturing in a ${ }^{14} \mathrm{C}$ medium containing $\mathrm{NaH}^{14} \mathrm{CO}_{3}$ for $10 \mathrm{~min}$. Incorporation of ${ }^{14} \mathrm{C}$ into starch occurred earlier than ulvan. After the hydrolysis of ulvan, the radioactivity of Rha was higher than that of GlcA, indicating that Rha deposition occurs earlier than GlcA deposition. Recent advances in analytical instruments such as mass spectrometry (MS) and nuclear magnetic resonance (NMR) allow for a more comprehensive analysis of fluxes of metabolites and material exchanges between organisms by stable isotope labelling ${ }^{26-28}$. Natural ${ }^{13} \mathrm{C}$ distribution is only $1.07 \%$, but concentrating ${ }^{13} \mathrm{C}$ makes structural analysis of metabolites by ${ }^{13} \mathrm{C}$-NMR spectroscopy easier. High performance liquid chromatography electron spray ionization mass spectrometry (HPLC ESI-MS) and GC-MS analysis of ${ }^{13} \mathrm{C}$-enriched metabolites enable tracing of the ${ }^{13} \mathrm{C}$ flux of each component. Further, FT-ICR-MS provides an accurate mass of metabolites that allows tracing of the metabolic foot print ${ }^{29}$.

This study demonstrated the behaviour of rapid carbon fixation in U. meridionalis and its transfer to polysaccharides through NDP sugars to understand the physiological mechanisms of their extremely high growth rate. U. meridionalis was cultured in enriched artificial seawater (EASW) ${ }^{30-32}$ medium with ${ }^{13} \mathrm{C}-\mathrm{NaHCO}_{3}$ as the sole carbon source, and the temporal ${ }^{13} \mathrm{C}$ transfer to NDP sugars and polysaccharides (ulvan and starch) was analysed. Incorporation of ${ }^{13} \mathrm{C}$ into NDP sugars was analysed using FT-ICR-MS. Semiquantitative ${ }^{13} \mathrm{C}-\mathrm{NMR}$ by inverse-gated-decoupling was used to observe ${ }^{13} \mathrm{C}$ incorporation into polysaccharides. GS-MS was used to trace ${ }^{13} \mathrm{C}$ uptake in monosaccharide moieties in polysaccharides after their acid hydrolysis. Finally, the flux of carbon fixation and its transfer into the cell wall polysaccharides was discussed in conjunction with the rapid growth rate of $U$. meridionalis.

\section{Results}

${ }^{13} \mathrm{C}$ uptake by $U$. meridionalis. Figure $1 \mathrm{~A}, \mathrm{~B}$ shows the changes in fresh weight and dry weight over time in light and dark conditions. The fresh weight shows linear increases over time, and it doubled in $24 \mathrm{~h}$. U. meridionalis grew up to about 3.5-fold in a day at the same light and temperature condition (12:12 light:dark regime, $\left.25^{\circ} \mathrm{C}\right)^{6}$. In the present study, the growth rate of U. meridionalis was lower because closed flasks were used for its cultivation, without aeration, to prevent an exchange of ${ }^{13} \mathrm{C}$ with ${ }^{12} \mathrm{C}$ in the atmosphere. Therefore, diffusion of oxygen, which is an inhibitor of the carboxylase activity of Rubisco, might not be sufficient, resulting in a lower growth rate than the ideal one. Moreover, ${ }^{13} \mathrm{C}$ uptake can be slower than ${ }^{12} \mathrm{C}$ uptake because of its larger mass. The dry weight of $U$. meridionalis increased by 1.8 times, and the amount of oxygen generated reached $49 \mathrm{~mL}$ after $12 \mathrm{~h}$ in the light period (Supplementary Fig. S1). In the dark period, the fresh weight increased linearly at the same rate as that under light, but the dry weight did not change. That is, photosynthetic metabolites accumulated in the light period to increase their dry weight. Meanwhile, water content increased during the dark period.

After powdering the dried sample, the amount of incorporated ${ }^{13} \mathrm{C}$ was measured by IR-MS. The ${ }^{13} \mathrm{C}$ uptake in the light period was $41.2 \%$, which was consistent with a doubling of dry weight under light (Fig. 1C). On the other hand, ${ }^{13} \mathrm{C}$ uptake was hardly observed in the dark period, indicating that the carbon fixation of $U$. meridionalis occurs in a light-dependent manner (Fig. 1D). Then, the elemental composition was investigated by CHNS analysis. The amounts of $\mathrm{C}(27.8 \%$ to $30.2 \%)$ and $\mathrm{H}(4.7 \%$ to $5.5 \%)$ reflected entire organic compounds, including sugar chains and proteins (Fig. 1E,F). The amount of $\mathrm{N}(3.0 \%$ to $3.9 \%)$ was mainly attributed to protein 

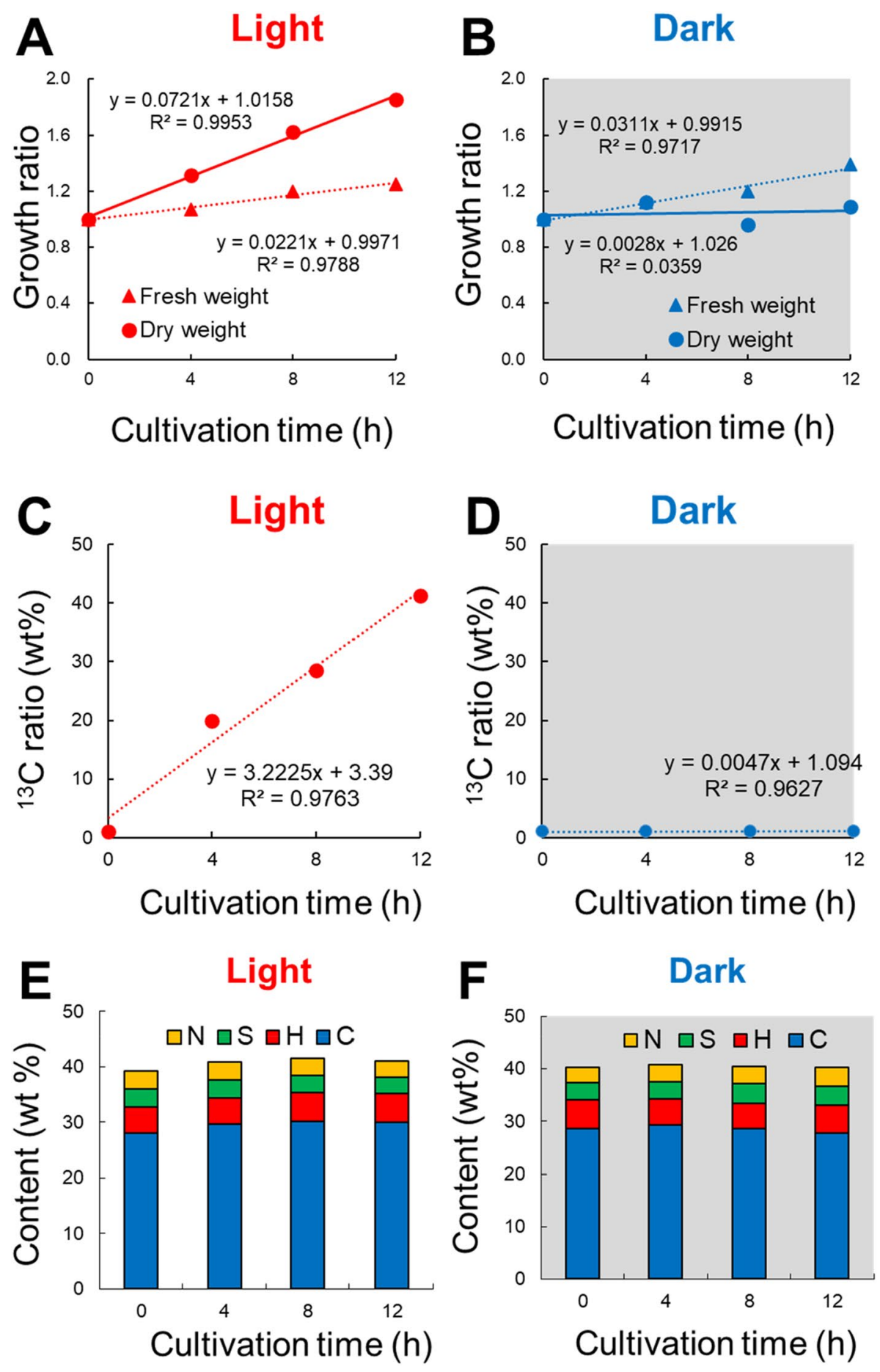

Figure $1 .{ }^{13} \mathrm{C}$ uptake by Ulva meridionalis under light and dark conditions. Fresh and dry growth rate under (A) light and (B) dark. ${ }^{13} \mathrm{C}$ uptake under (C) light and (D) in the dark. The elemental composition of ${ }^{13} \mathrm{C}$-labelled U. meridionalis under (E) light and (F) dark.

and that of S (2.9\% to $3.9 \%)$ was attributed to the sulphate groups of sugar chains such as ulvan. There was no change in the ratio of carbon, hydrogen, nitrogen, and sulfur in both light and dark periods throughout the cultivation. This suggests that the elemental composition of $U$. meridionalis is always constant regardless of the extensive accumulation of photosynthetic products during the light period. The carbon uptake by U. meridionalis was measured from the dry weight, and carbon content was obtained by CHNS analysis. The amount of carbon fixed per unit dry algae reached $16.8 \mathrm{mg} \mathrm{C}$ fixed g dry wt $\mathrm{t}^{-1} \mathrm{~h}^{-1}(0-4 \mathrm{~h}), 15.7 \mathrm{mg} \mathrm{C}$ fixed g dry wt $\mathrm{f}^{-1}(4-8 \mathrm{~h})$, and $13.7 \mathrm{mg} \mathrm{C}$ fixed g dry $\mathrm{wt}^{-1} \mathrm{~h}^{-1}(8-12 \mathrm{~h})$, which exceeded those of tubular and sheet-like Ulva sp. (5.16 mg $\mathrm{C}$ fixed g dry $\mathrm{wt}^{-1} \mathrm{~h}^{-1}$ on average) reported by Littler et al. ${ }^{33}$. 


\begin{tabular}{|l|l|l|l|l|}
\hline NDP sugar & $\begin{array}{l}\text { Corresponding } \\
\text { monosaccharide(s) }\end{array}$ & Number of carbons & $\begin{array}{l}\text { observed Monoisotopic mass } \\
\left(\mathbf{m}_{\mathbf{0}}, \boldsymbol{m} / \boldsymbol{z}\right)\end{array}$ & ${ }^{{ }^{3} \mathbf{C}-\text { labeled mass }(\boldsymbol{m} / \boldsymbol{z})}$ \\
\hline UDP-pentose & Xyl & 14 & 535.05264 & 549.10112 \\
\hline UDP-deoxy-hexose & Rha & 15 & trace $(549)$ & trace $(564)$ \\
\hline UDP-hexose & Glc, Gal & 15 & 565.06293 & 580.11671 \\
\hline UDP-hexuronic acid & GlcA & 15 & 579.04417 & 594.09604 \\
\hline UDP- $N$-acetyl-hexose & Not identified & 17 & 606.09319 & 623.15260 \\
\hline
\end{tabular}

Table 1. Accurate mass analysis of nucleic diphosphate sugars by FT-ICR-MS.

Incorporation of ${ }^{13} \mathrm{C}$ in NDP sugars. Subsequently, NDP sugar was extracted according to the method of Räbina et al. ${ }^{34}$, and the incorporation of ${ }^{13} \mathrm{C}$ into the NDP sugar was measured by FT-ICR-MS. Low molecular weight compounds such as pigments were first extracted from U. meridionalis samples with $75 \%$ aqueous ethanol. The amount of ethanol extract used was consistent over time and was $37.7 \pm 4.5 \%$ on average during both light and dark periods (Supplementary Fig. S2). 75\% aqueous ethanol extract was dissolved in aqueous $\mathrm{NaHCO}_{3}$, and the soluble fraction was applied to ENVIcarb solid-phase extraction (SPE) cartridge. This column is suitable for the separation of highly polar compounds. Highly polar NDP sugars were adsorbed into the column, and then the NDP sugar was eluted with $25 \%$ acetonitrile containing triethylammonium acetate buffer (TEAA; $50 \mathrm{mM}, \mathrm{pH} 7$ ) to recover NDP sugars. The NDP sugar was analysed by FT-ICR-MS equipped with ESI (Bruker solariX). The MS spectra were recorded in negative-ion mode since the NDP sugars are negatively charged. Table 1 shows the carbon number, monoisotopic mass, and $\mathrm{m} / \mathrm{z}$ of ${ }^{13} \mathrm{C}$-labelled UDP-pentose, UDPdeoxyhexose, UDP-hexose, and UDP-hexuronic acid as precursors of ulvan and starch. The monoisotopic mass is indicated as $M_{0}$, and the mass changes from $M_{0}$ to $M_{0+15}$, depending on the carbon number of each NDP sugar (carbon numbers $=14$ or 15 ) by ${ }^{13} \mathrm{C}$ labelling, were analysed. For example, UDP-pentose with 14 carbons $\left(\mathrm{M}_{0}=535\right)$, which corresponds to the precursor of Xyl, exhibits $\mathrm{M}_{0+14}$ when it is completely labelled with ${ }^{13} \mathrm{C}$. Similarly, UDP-hexose and UDP-hexuronic acid correspond to precursors of Glc and Gal and GlcA, respectively.

Figure 2 shows the temporal change in the FT-ICR-MS spectrum of ${ }^{13} \mathrm{C}$-labelled NDP sugars. Peaks with $\mathrm{m} / \mathrm{z}$ corresponding to UDP-pentose, UDP-hexose, and UDP-hexuronic acid were detected. On the other hand, UDPdeoxyhexose, which is considered to be a precursor of Rha, was not detected. Similarly, dTDP-Rha $\left(M_{0}=547\right)$, which is the precursor of Rha in microorganisms, was not detected. In addition, $\mathrm{m} / \mathrm{z}$ corresponding to UDP-Nacetyl-hexose was detected in both light and dark periods. However, the corresponding monosaccharide to UDP$\mathrm{N}$-acetyl-hexose has not been identified. Since the ${ }^{13} \mathrm{C}$ labelling may cause an overlap in $\mathrm{M}_{0+\mathrm{x}}$ peaks of several compounds, FT-ICR-MS measurement of non-labelled NDP sugars was also performed using U. meridionalis cultured in a non-labelled medium under the same conditions (Supplementary Fig. S3). The monoisotopic mass peaks corresponding to above NDP sugars were detected; thus, their presence was confirmed.

In Fig. $2 \mathrm{C}-\mathrm{H}$, the changes in the mass of each NDP sugar are extracted, and they were expressed as the ratio of the individual masses to the sum of $\mathrm{M}_{0}$ to $\mathrm{M}_{0+\mathrm{X}}(\mathrm{X}=14,15) .{ }^{13} \mathrm{C}$ was rapidly incorporated into NDP sugars under light conditions. After $4 \mathrm{~h}$ of ${ }^{13} \mathrm{C}$ labelling, $\mathrm{M}_{0+14}$ (UDP-pentose) and $\mathrm{M}_{0+15}$ (UDP-hexose, UDP-hexuronic acid) were the major peaks followed by partially labelled peaks of $\mathrm{M}_{0}$ to $\mathrm{M}_{0+14}$. The ratio of ${ }^{13} \mathrm{C}$ incorporated in UDP-hexose was constant at 4-8 h. After $12 \mathrm{~h}$, the peak of $\mathrm{M}_{0+15}$ increased; however, $\mathrm{M}_{0+15}$ did not reach $100 \%$ even after $12 \mathrm{~h}$. This suggested that Ulva also used non-labelled metabolites, which were accumulated before ${ }^{13} \mathrm{C}$ labelling, for production of NDP sugars. With UDP-hexuronic acid, the peak of $\mathrm{M}_{0+15}$ at $12 \mathrm{~h}$ reached $70 \%$ of the total, suggesting that the UDP-GlcA was generated from ${ }^{13} \mathrm{C}$-labeled UDP-Glc. On the other hand, UDPpentose showed lesser uptake of ${ }^{13} \mathrm{C}$ than that of UDP-hexose and UDP-hexuronic acid. ${ }^{13} \mathrm{C}$ incorporation into UDP-pentose was slow because the formation of UDP-Xyl is downstream of UDP-GlcA formation. During the dark period, ${ }^{13} \mathrm{C}$ uptake was much lower than that in the light period, but ${ }^{13} \mathrm{C}$ uptake still occurred to some extent. Peaks corresponding to $\mathrm{M}_{0+1}$ to $\mathrm{M}_{0+2}$ were observed and increased over time. Carbon fixation, also called dark reaction, proceeded even in the absence of light. However, carbon uptake was particularly low in the dark period.

Incorporation of ${ }^{13} \mathrm{C}$ in ulvan and starch. The transfer of ${ }^{13} \mathrm{C}$ to matrix polysaccharides and starch of $U$. meridionalis was investigated using ${ }^{13} \mathrm{C}-\mathrm{NMR}$. Polysaccharides were recovered through hot water extraction $\left(90^{\circ} \mathrm{C}, 1 \mathrm{~h} \times 3\right)$ of residues after $75 \%$ aqueous ethanol extraction. The polymers in the hot water extract were recovered through ethanol precipitation. After freeze-drying, the incorporation of ${ }^{13} \mathrm{C}$ into the hot water extract was evaluated by IR-MS. This fraction contained starch and ulvan but was not purified further because the amount of extract was small. Figure $3 \mathrm{~A}$ shows the ${ }^{13} \mathrm{C}$ ratio in the hot water extract. The incorporation rate of ${ }^{13} \mathrm{C}$ into polysaccharides was the same as that for the whole algae body because their slopes were almost the same. Then, the hot water extract was dissolved in a mixed solvent of $\mathrm{D}_{2} \mathrm{O}-\mathrm{DMSO}-d_{6}$ and analysed by ${ }^{13} \mathrm{C}-\mathrm{NMR}$. Inverse-gated-decoupling provided the quantitative ${ }^{13} \mathrm{C}$ spectra with ${ }^{1} \mathrm{H}$ decoupling with a sufficient relaxation time of the $T_{1}{ }^{13} \mathrm{C}^{35}$. However, in the present study, the repetition time was set to $10.69206 \mathrm{~s}$ since the $T_{1}{ }^{13} \mathrm{C}$ was long ${ }^{36}$. DMSO- $d_{6}$ contained in the solvent was used as an internal standard to determine the amount of ${ }^{13} \mathrm{C}$ uptake into each carbon-containing ulvan.

Figure 3B,C shows the semiquantitative ${ }^{13} \mathrm{C}$-NMR spectra of the hot water extract during the light and dark periods. A clear chemical shift was observed in the light period, and the intensity increased with time. These chemical shifts were similar to those of U. armoricana ulvan because there were similar signals for G1, Gg1, R'1, and R1 at around $100 \mathrm{ppm}^{23}$. Chemical shifts in the range of $60 \mathrm{ppm}-100 \mathrm{ppm}$ were attributed to C-OH of sugar moieties, but they were difficult to analyse in detail because they overlapped with each other. Therefore, 

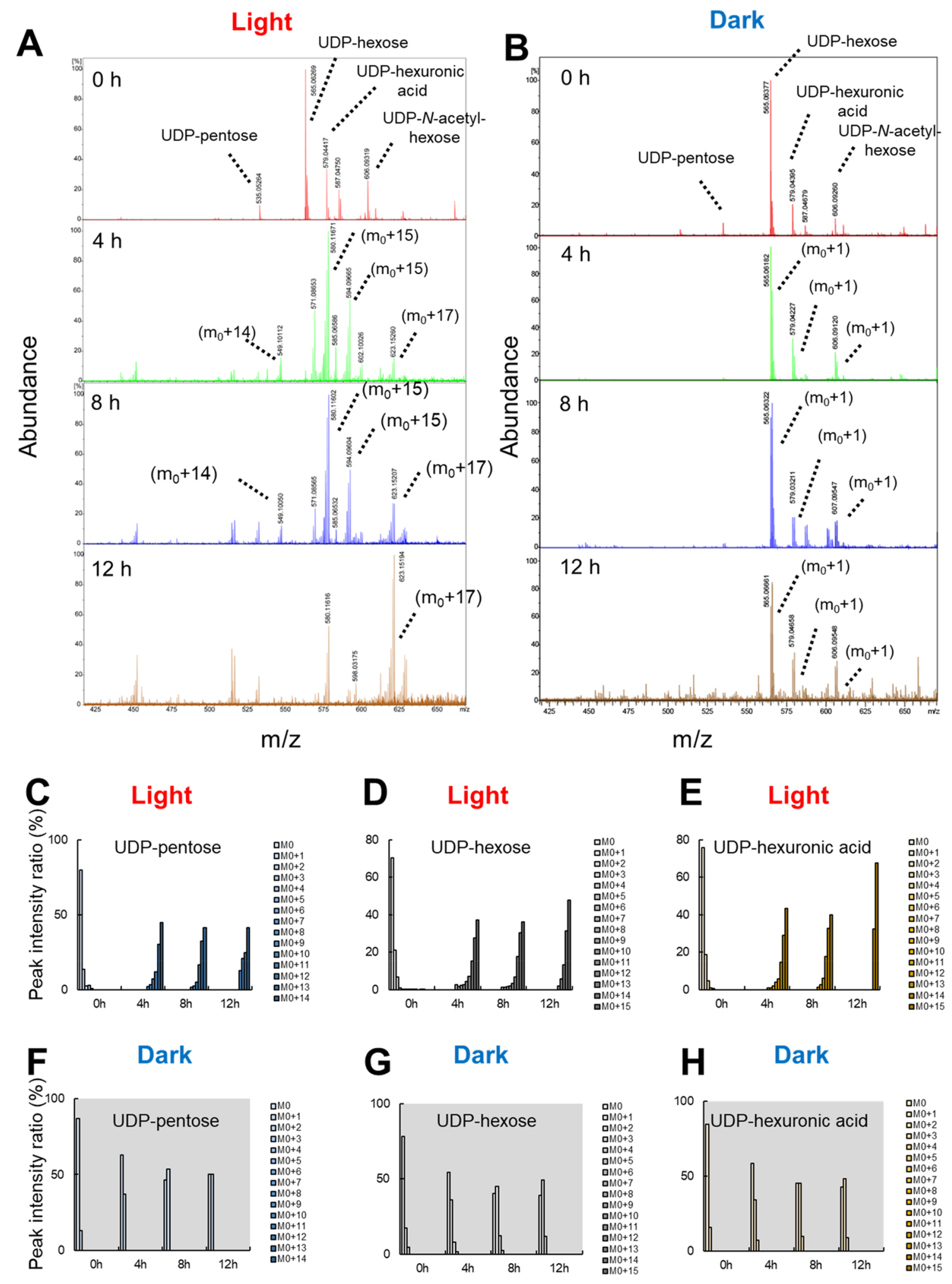

Figure 2. FT-ICR-MS analysis of ${ }^{13} \mathrm{C}$-incorporated nucleic diphosphate sugars produced under (A) light and (B) dark conditions. Comparisons of monoisotopic mass $\left(\mathrm{M}_{0}\right)$ and ${ }^{13} \mathrm{C}$-labelled mass $\left(\mathrm{M}_{0+\mathrm{X}}, \mathrm{X}=1-15\right)$ under (C-E) light and (F-H) dark.

the signals at 17 ppm due to C-6 of Rha and 176 ppm due to the carboxyl group of C-6 of GlcA were analysed because they were completely separate from the other signals. A normalised intensity against those of $0 \mathrm{~h}$ is summarised in Fig. 3D. The transfer of ${ }^{13} \mathrm{C}$ to Rha and GlcA occurs later compared with the transfer of ${ }^{13} \mathrm{C}$ to the 
A

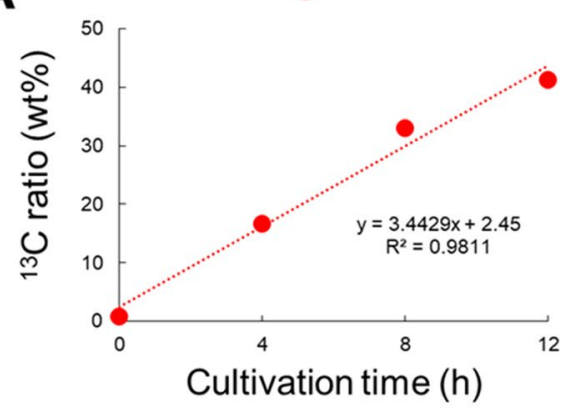

B

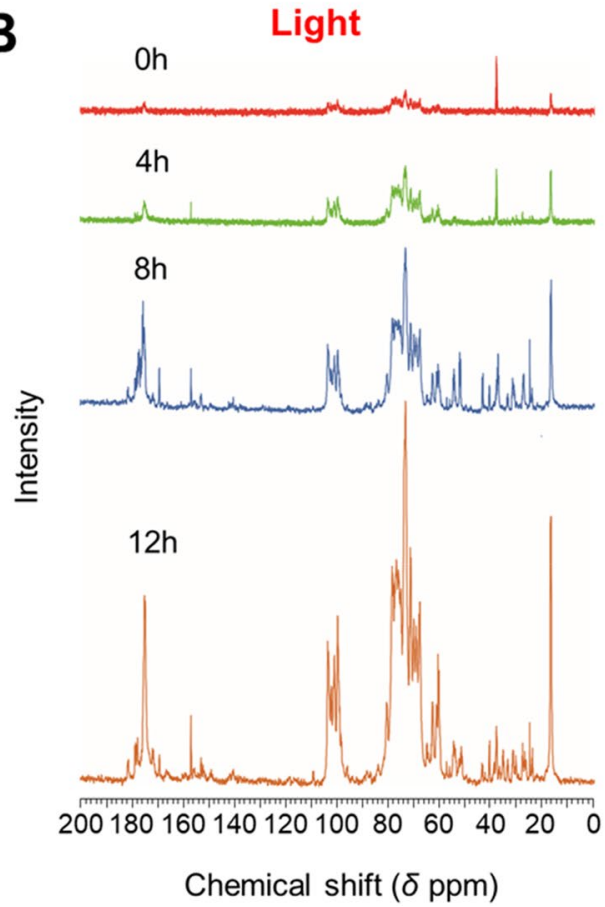

D

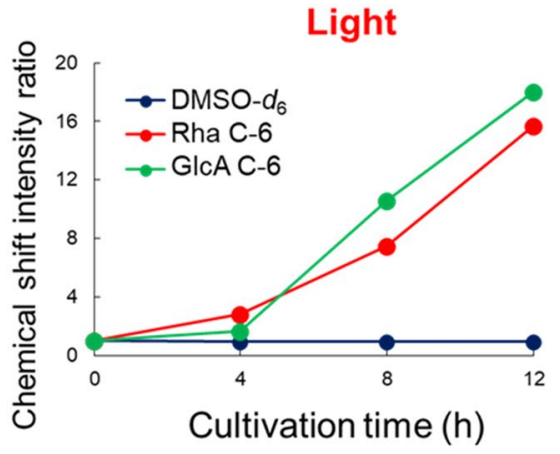

C

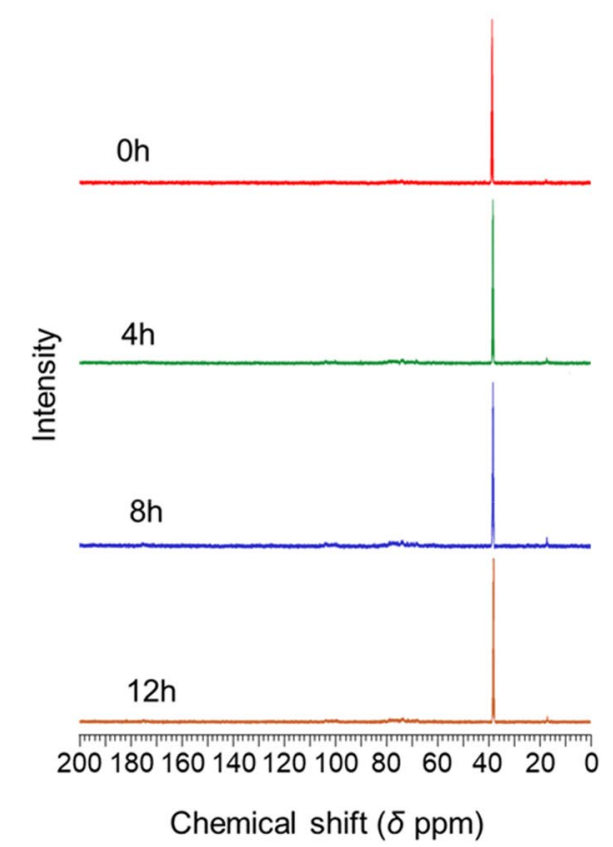

Figure 3. (A) The amount of incorporated ${ }^{13} \mathrm{C}$ in the hot water extract as cultivation time increased. ${ }^{13} \mathrm{C}-\mathrm{NMR}$ spectra of ${ }^{13} \mathrm{C}$-labelled ulvan extracted from Ulva meridionalis cultivated under (B) light and (C) dark. (D) Temporal changes in the chemical shift intensities of Rha C-6 and GlcA C-6.

hot water extract. The intensity did not change so much at $4 \mathrm{~h}$ but then increased from $8 \mathrm{~h}$ and finally reached about 16 times that of the initial intensity by $12 \mathrm{~h}$. This suggests that the rate of Rha and GlcA incorporation into ulvan are almost the same. On the other hand, no clear signals other than that of DMSO- $d_{6}$ were observed in the dark period.

Incorporation of ${ }^{13} \mathrm{C}$ in monosaccharides in ulvan and starch. Further, ${ }^{13} \mathrm{C}$ incorporation at the monosaccharide level was analysed by GC-MS. Hot water extracts were hydrolysed with TFA (2 M), derivatised to alditol acetate, and then analysed by GC-MS. Figure 4A,B show the weight ratio of Rha, Xyl, Man, Glc, and Gal. Rha and Xyl were attributed to ulvan, while Glc was attributed to starch. Therefore, we focused on the ${ }^{13} \mathrm{C} /{ }^{12} \mathrm{C}$ ratios of Rha and Glc as representatives of ulvan and starch. The ratio of Rha was the highest in all conditions. On the other hand, Glc varied greatly depending on the cultivation time. In the light period, the Glc ratio increased from 0 to $8 \mathrm{~h}$. This Glc increase was attributed to starch production during the light period. Then, the Rha ratio increased up to $12 \mathrm{~h}$ due to the deposition of ulvan and resulted in a relatively low Glc ratio. During the dark period, the Glc ratio gradually decreased with time. This is probably because the starch synthesised in the light period was consumed in the dark period. Therefore, the ratio of Rha and Xyl gradually increased as the ratio of Glc decreased.

The incorporation of ${ }^{13} \mathrm{C}$ into each monosaccharide was investigated in detail using EI-MS spectra. Figure $4 \mathrm{C}$ shows changes in typical fragmentation patterns of neutral sugars due to the introduction of ${ }^{13} \mathrm{C}$. Replacement of the fragment ions with ${ }^{13} \mathrm{C}$ changes $\mathrm{m} / \mathrm{z}$ from +1 to +4 . Figure $4 \mathrm{D}-\mathrm{G}$ show temporal changes in the fragmentation patterns of each neutral sugar in the light period. The $\mathrm{m} / \mathrm{z}$ changes following the incorporation of ${ }^{13} \mathrm{C}$ are highlighted with bold lines and red letters. For example, in Rha, a fragment corresponding to $\mathrm{m} / \mathrm{z} 217$ began to 
A

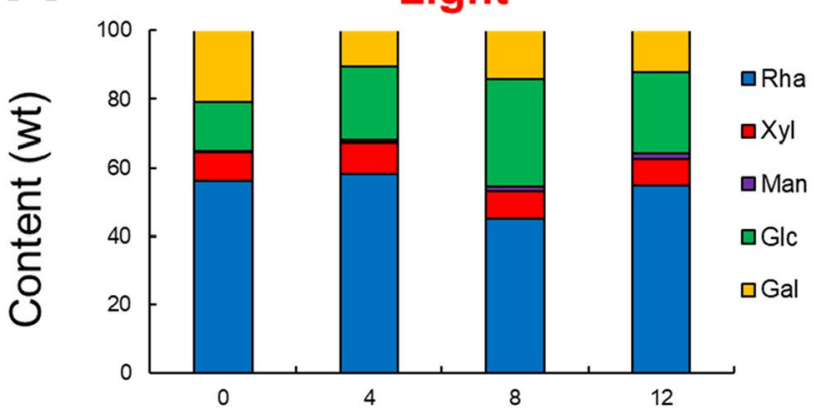

Cultivation time $(h)$
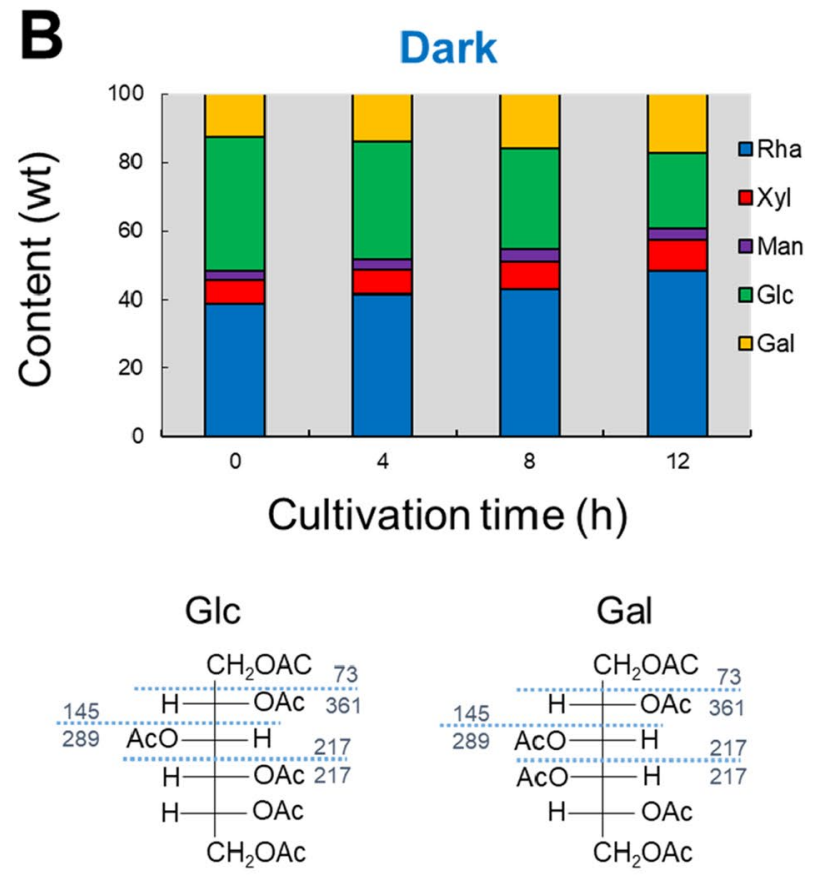
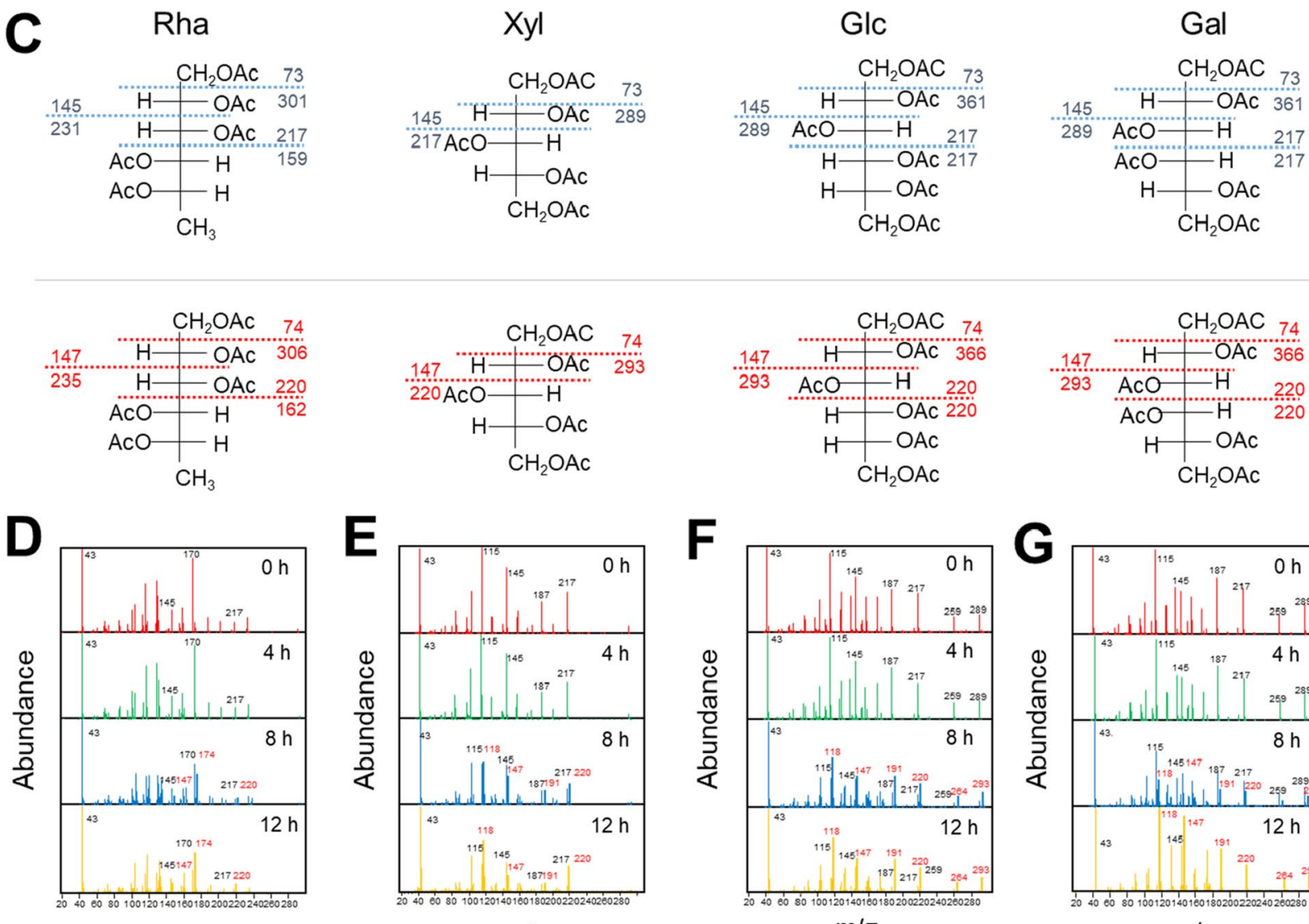

$m / z$
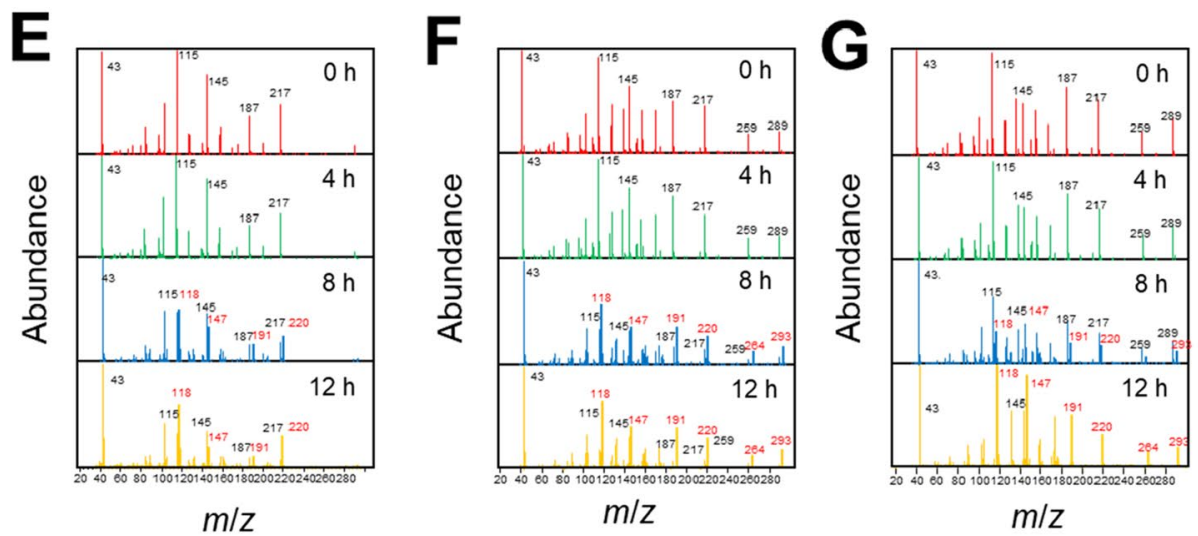

Figure 4. EI-MS spectra of alditol acetate derivatives of neutral sugars obtained by hydrolysis of ulvan extracted from U. meridionalis cultivated under light. Monosaccharide composition of hot-water extracts obtained under (A) light and (B) dark periods. (C) Fragmentation patterns of alditol acetate derivatives of neutral sugars with and without ${ }^{13} \mathrm{C}$-labelling. EI-MS spectra of (D) rhamnose, (E) xylose, (F) glucose, and (G) galactose.

migrate to 220 in $8 \mathrm{~h}$. The peak intensity of 220 was 2.1 times higher than that of 217 at $12 \mathrm{~h}$. The average ${ }^{13} \mathrm{C} /{ }^{12} \mathrm{C}$ ratio in Rha was about 1.3 after $12 \mathrm{~h}$ (Supplementary Table S2). On the other hand, the average ${ }^{13} \mathrm{C} /{ }^{12} \mathrm{C}$ ratio in Glc was 3.8 after $12 \mathrm{~h}$, which was higher than that of Rha (Supplementary Table S2). This indicates that the vigorous starch biosynthesis in the light period increases the level of ${ }^{13} \mathrm{C}$ incorporation into Glc. On the other hand, ulvan biosynthesis represented by the ${ }^{13} \mathrm{C} /{ }^{12} \mathrm{C}$ ratio of Rha was slower than starch biosynthesis.

\section{Discussion}

This study performed ${ }^{13} \mathrm{C}$ labelling cultivation of $U$. meridionalis to understand the mechanisms by which they grow up to fourfold a day. We tracked the fresh and dry weight changes, ${ }^{13} \mathrm{C}$ uptake in whole algae, the formation of NDP sugars, matrix polysaccharides, and monosaccharides during the light and dark periods. Compared to the previous ${ }^{14} \mathrm{C}$ labelling of $U l v a^{25}$, enriched ${ }^{13} \mathrm{C}$ was useful to track the carbon fixation into matrix and storage polysaccharides through NDP sugars by using IR-MS, FT-ICR-MS, ${ }^{13} \mathrm{C}-\mathrm{NMR}$ and GC-MS. In the light period, 

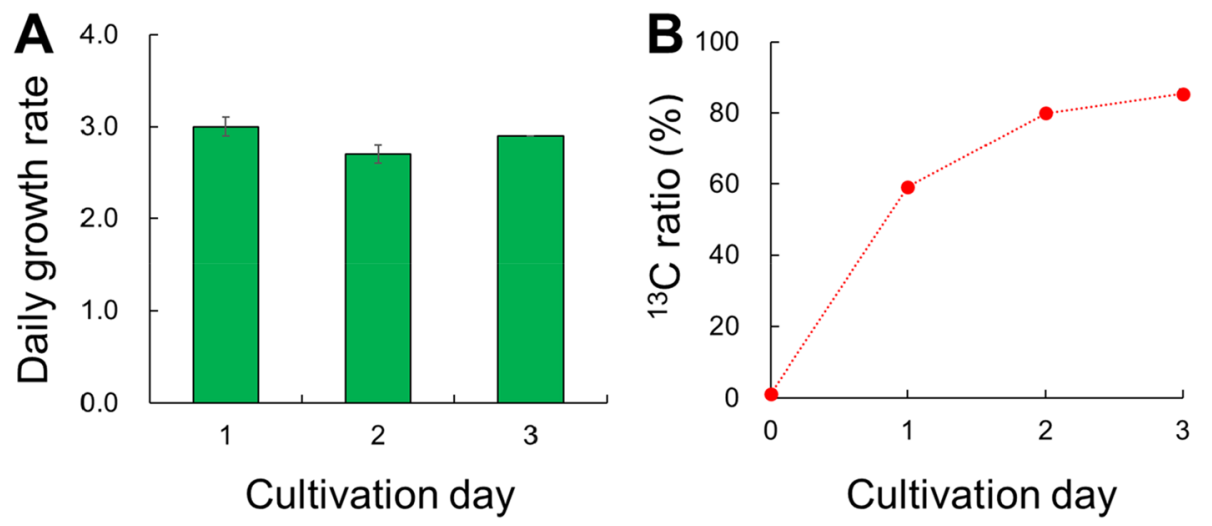

Figure 5. The ${ }^{13} \mathrm{C}$ concentrating cultivation of Ulva meridionalis. (A) Daily growth rate and (B) ${ }^{13} \mathrm{C}$ ratio.

photosynthesis promotes strong carbon fixation. Carbon fixed in the Calvin cycle is converted into UDP-Glc via fructose 6-phosphate and then UDP-GlcA and UDP-Xyl. Labelling of these NDP sugars already occurred at an early stage after the start of the light period. Meanwhile, the transfer of ${ }^{13} \mathrm{C}$ to matrix polysaccharides was delayed by the formation of NDP sugars and occurred more than $4 \mathrm{~h}$ after the start of the light period. Percival et al. studied carbon fixation in $U$. lactuca using radioactive ${ }^{14} \mathrm{C}$ as a tracer and found that sucrose was the earliest product, detected $10 \mathrm{~min}$ after labelling, followed by starch formation ${ }^{25}$. Then, ulvan was formed after a delay of about $3 \mathrm{~h}$. Therefore, $U$. meridionalis has a similar sugar biosynthesis system to that of $U$. lactuca. However, the carbon fixation speed by $U$. meridionalis further exceeded the average primary productivity by other thin tubular and sheet-like seaweeds (mainly Ulva seaweeds) by 2.65-3.26-fold ${ }^{33}$.

The change in fresh weight during growth did not show a large difference between the light and the dark periods (Fig. 1A,B). This was also confirmed by the growth behaviour when cultured in the unlabelled medium (Supplementary Fig. S5A). On the other hand, the change in dry weight differed greatly between the light and the dark periods. The dry weight increased clearly in the light period, but there was almost no change in the dark period. The similar behaviour was also observed with the unlabelled medium (Supplementary Fig. S5B). This indicates that most of the carbon fixation products are obtained by photosynthesis during the light period, which is completely consistent with the ${ }^{13} \mathrm{C}$ uptake behaviour. Meanwhile, water content increased during the dark period. As a result, the fresh weight increased linearly in both light and dark periods.

Based on the above carbon uptake behaviours, we turned to prolong the light period to test if it is an effective method of accumulating more fixed carbon and promoting growth. Greater carbon fixation will be effective for biomass production and carbon dioxide fixation. Supplementary Fig. S4 shows the growth behaviour when the light:dark regime was varied from $12: 12$ to $24: 0$. Under a light:dark regime of 14:10, the daily growth rate increased, however, the growth rate did not increase when the light period was prolonged above $14 \mathrm{~h}$. This suggests that the dark period is also important for U. meridionalis growth. According to Hiraoka et al., cell division should occur at least twice a day to grow fourfold a day ${ }^{6}$. According to Kuwano et al., the cell division cycle of U. partita (=Enteromorpha compressa in Kuwano et al.) is controlled by the diurnal cycle, and a dark period is required for $6 h^{37}$. During the dark period, the number of cells increase by cell division. That is, cell division occurs using photosynthetic metabolites produced under the light period. In fact, the percentage of Glc in the hot water extract-hydrolysate reduced in the dark period. This indicates that starch is consumed as an energy source for cell division. In addition, McArthur et al. reported that cell wall deposition occurs at the end of cytokinesis through light and electron microscopy of $U$. intestinalis during mitosis ${ }^{38}$. That is, the ulvan obtained during the light period also contributes to the formation of the cell wall, accompanying cell division during the dark period.

The optimal light:dark regime of $U$. meridionalis was the long-day condition of around 14:10. This is consistent with the fact that $U$. meridionalis was first discovered in summer and grows at high water temperatures ${ }^{7}$. Then, we examined how much carbon could be fixed by $U$. meridionalis using ${ }^{13} \mathrm{C}$ labelling under the light:dark regime of 14:10. A closed flask bubbling with $\mathrm{N}_{2}$ gas was used to enable long-term ${ }^{13} \mathrm{C}$ labelling (Supplementary Fig. S6). The same ${ }^{13} \mathrm{C}$-labelled EASW mentioned above was added to the flask and filled with nitrogen gas so as not to contact the ${ }^{12} \mathrm{C}$ in the atmosphere. Nitrogen gas was circulated using a diaphragm pump to appropriately agitate the algal bodies. The ${ }^{13} \mathrm{C}$ medium was replaced every $24 \mathrm{~h}$ so that the medium was always fresh. Under these conditions, U. meridionalis grew three times each day (Fig. 5A). Uptake of ${ }^{13} \mathrm{C}$ at $72 \mathrm{~h}$ reached approximately $85 \%$. This confirms the very high carbon fixation capacity of $U$. meridionalis (Fig. 5B).

In conclusion, the high growth rate of $U$. meridionalis is associated with its strong carbon fixation ability. Through ${ }^{13} \mathrm{C}$ labelling in the light period, the NDP sugar was rapidly labelled as the precursor of polysaccharides; then, ${ }^{13} \mathrm{C}$ was transferred to ulvan later. In contrast, carbon uptake hardly occurred in the dark period. Cell division was carried out in the dark period using the carbon fixed during the light period. For instance, the accumulated starch may be used as an energy source for cell division. Further, ulvan may be used for cell wall formation at the end of cell division. Under optimal long-day conditions, $90 \%$ of ${ }^{13} \mathrm{C}$ labelling was achieved within $72 \mathrm{~h}$. We conclude that $U$. meridionalis exhibits a high carbon fixation capacity that contributes to its high growth potential. 


\section{A}

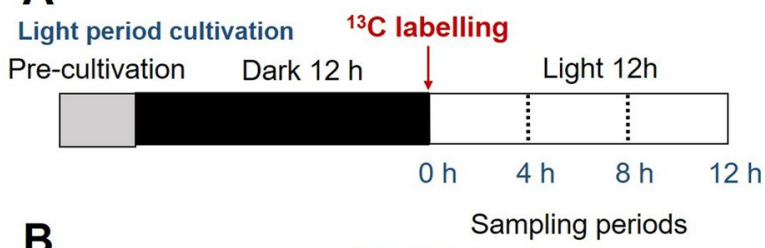

B

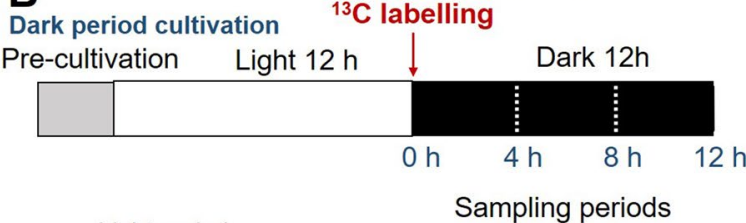

Light period

C

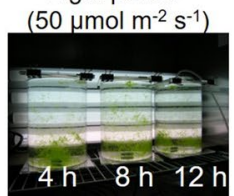

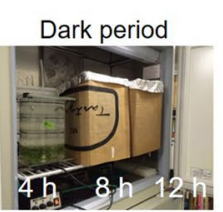

Shields to prevent light breaking

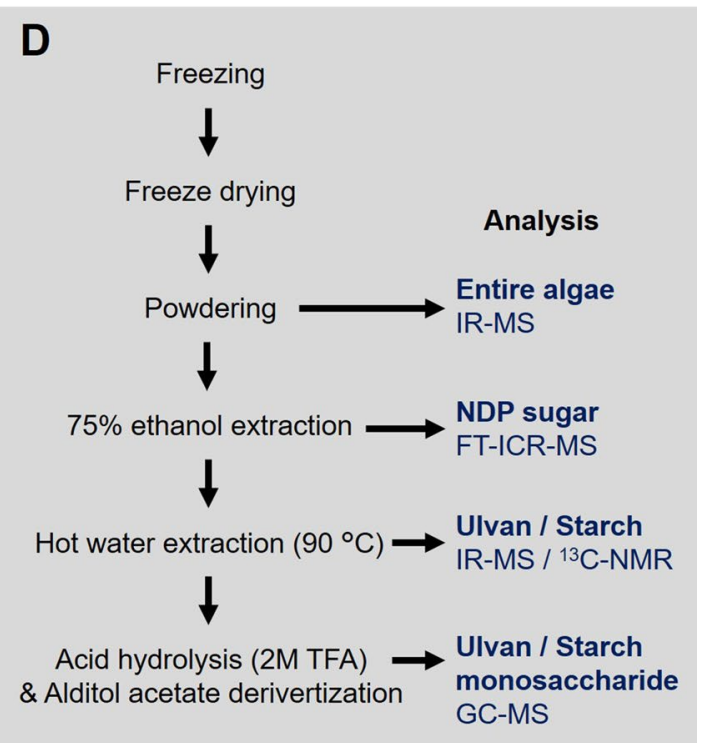

Figure 6. The ${ }^{13} \mathrm{C}$ labelling and sampling periods of Ulva meridionalis under (A) light and (B) dark. (C) The photographs of each cultivation tank for sampling U. meridionalis after 4-12 h. (D) Fractionations and analyses of nucleic diphosphate sugar, ulvan / starch, and ulvan / starch monosaccharides.

\section{Methods}

Pre-cultivation of $U$. meridionalis. The pre-cultivation of $U$. meridionalis was conducted according to the procedure of Hiraoka et al. ${ }^{6}$. Namely, U. meridionalis stock was transferred to non ${ }^{13} \mathrm{C}$ labelled EASW (Supplementary Table S1) for 8 days $^{30-32}$. The light irradiation was operated at $50 \mu \mathrm{mol} \mathrm{m}{ }^{-2} \mathrm{~s}^{-1}$ under a light:dark regime of 12:12. The EASW medium was exchanged every second day. The flask size was gradually increased from $1 \mathrm{~L}$ (4 days) to $2 \mathrm{~L}$ ( 2 days) and $5 \mathrm{~L}$ (2 days) depending on the growth of $U$. meridionalis during pre-cultivation (Supplementary Fig. S7). All cultivation were performed at $25^{\circ} \mathrm{C}$. The $U$. meridionalis were mixed using a stirring bar.

${ }^{13} \mathrm{C}$ labelling of $U$. meridionalis. Figure $6 \mathrm{~A}, \mathrm{~B}$ show the schedule for ${ }^{13} \mathrm{C}$-labelling cultivation and sampling of $U$. meridionalis. First, U. meridionalis, in a vegetative growth stage, was pre-cultured using non-labelled EASW under a 12:12 light:dark regime. U. meridionalis was transferred into a ${ }^{13} \mathrm{C}$-labelled EASW medium containing ${ }^{13} \mathrm{C}-\mathrm{NaHCO}_{3}$ (99\%, Cambridge Isotope Laboratories Inc., MA, USA). as the sole carbon source (Supplementary Table S1). ${ }^{13} \mathrm{C}$-labelled $U$. meridionalis was collected every $4 \mathrm{~h}$ under light $\left(50 \mu \mathrm{mol} \mathrm{m} \mathrm{m}^{-2} \mathrm{~s}^{-1}\right)$ and dark periods (Fig. 6A-C). The medium was homogeneously mixed by a stirring bar. The apparent amount of $\mathrm{O}_{2}$ generation was monitored from the amount of the gas emitted from the cultivation tank. After collecting the ${ }^{13} \mathrm{C}$-labelled $U$. meridionalis, their fresh weight was measured, then immediately frozen, lyophilised, and powdered to measure the dry weight (Fig. 6D). The total amount of incorporated ${ }^{13} \mathrm{C}$ was measured by IR-MS (RMI-2, Hitachi, Ltd., Tokyo, Japan). The approximate elemental analysis was performed using the CHNS analyser (FlashEA 1112; Thermo Fisher Scientific Inc., MA, USA). Dried samples were further used for NDP sugar and polysaccharide analyses (Fig. 6D).

NDP sugar analysis by FT-ICR-MS. NDP sugars were extracted and purified by SPE according to the methods of Räbina et al. with slight modifications ${ }^{34}$. Namely, the dried powders of $U$. meridionalis were extracted three times with $75 \%$ aqueous ethanol, and then the extracts were dried using an evaporator. The dried extracts were suspended in aqueous $\mathrm{NaHCO}_{3}(10 \mathrm{mM})$ solution. The solubilised fractions were loaded on the ENVICarb SPE cartridge (Sigma-Aldrich Co. LLC., MO, USA). The SPE cartridge was successively washed with ultrapure water, TEAA buffer (50 mM, pH 7, Wako Pure Chemical Industries Ltd., Kyoto, Japan) solution, and 25\% aqueous acetonitrile solution. The cartridge was finally eluted with $25 \%$ aqueous acetonitrile containing TEAA. The extracted NDP-sugars were analysed by the Bruker solariX FT-ICR-MS (Bruker Co., MA, USA) operated

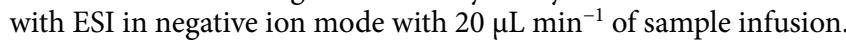

Ulvan analysis by semiquantitative ${ }^{13}$ C-NMR and GC-MS. Ulvan was extracted from the residue following aqueous ethanol $(75 \%)$ extraction with hot water $\left(90^{\circ} \mathrm{C}, 1 \mathrm{~h} \times 3\right)$. Ulvan was recovered by ethanol precipitation and then freeze-dried. The ${ }^{13} \mathrm{C}$ uptake in ulvan was measured by IR-MS. Semiquantitative ${ }^{13} \mathrm{C}-$ NMR of ${ }^{13} \mathrm{C}$-labelled ulvan was performed by the inverse-gated decoupling method using JEOL NMR ECA600 $(150 \mathrm{MHz})^{35,36}$. Ulvan was re-solubilised in $\mathrm{D}_{2} \mathrm{O}-\mathrm{DMSO}-d_{6}(92: 8)$ mixed solvent. NMR spectra were recorded at $40{ }^{\circ} \mathrm{C}$ with a repetition time of $10.69206 \mathrm{~s}$. The chemical shift intensities were normalised to the DMSO- $d_{6}$ internal standard. The monosaccharide composition of ulvan was analysed by GC-MS (Agilent GC $8690 \mathrm{~N}$ and MS 5973; Agilent Technologies, CA, USA). Ulvan was hydrolysed into monosaccharides by aqueous trifluoro 
acetate (TFA; $2 \mathrm{M}, 121^{\circ} \mathrm{C}, 1 \mathrm{~h}$ ). After removing TFA, the monosaccharides were derivatised to alditol acetate and analysed by GC-MS with a column of CBP-1 (Shimadzu GLC Ltd., Kyoto, Japan) operated at $140-160{ }^{\circ} \mathrm{C}$ $\left(2{ }^{\circ} \mathrm{C} \mathrm{min}^{-1}\right)$.

\section{Data availability}

All relevant data are included in the main text and Supplementary Information.

Received: 5 October 2020; Accepted: 9 November 2020

Published online: 23 November 2020

\section{References}

1. Smetacek, V. \& Zingone, A. Green and golden seaweed tides on the rise. Nature 504, 84-88 (2013).

2. Zhang, J. et al. Growth characteristics and reproductive capability of green tide algae in Rudong coast, China. J. Appl. Phycol. 25, 795-803 (2013).

3. Gao, S. et al. A strategy for the proliferation of Ulva prolifera, main causative species of green tides, with formation of sporangia by fragmentation. PLoS ONE 5, e8571 (2010).

4. Liu, F. et al. Understanding the recurrent large-scale green tide in the Yellow Sea: Temporal and spatial correlations between multiple geographical, aquacultural and biological factors. Mar. Environ. Res. 83, 38-47 (2013).

5. Wei, N., Quarterman, J. \& Jin, Y. S. Marine macroalgae: An untapped resource for producing fuels and chemicals. Trends Biotechnol. 31, 70-77 (2013).

6. Hiraoka, M. et al. Fourfold daily growth rate in multicellular marine alga Ulva meridionalis. Sci. Rep. 10, 12606 (2020).

7. Horimoto, R., Masakiyo, Y. \& Ichihara, K. Enteromorpha-like Ulva (Ulvophyceae, Chlorophyta) growing in the Todoroki River, Ishigaki Island, Japan, with special reference to Ulva meridionalis Horimoto et Shimada, sp. nov.. Bull. Natl. Mus. Nat. Sci. B 37, 155-167 (2011).

8. Tsubaki, S. et al. Hydrolysis of green-tide forming Ulva spp. by microwave irradiation with polyoxometalate clusters. Green Chem. 16, 2227-2233 (2014).

9. Onda, A. et al. Catalytic hydrolysis of polysaccharides derived from fast-growing green macroalgae. ChemCatChem $9,2638-2641$ (2017).

10. Tsubaki, S., Oono, K., Hiraoka, M., Onda, A. \& Mitani, T. Microwave-assisted hydrothermal extraction of sulfated polysaccharides from Ulva spp. and Monostroma latissimum. Food Chem. 210, 311-316 (2016).

11. Tsubaki, S., Zhu, W. \& Hiraoka, M. Production and Conversion of Green Macroalgae (Ulva spp.). In Fuels Chemicals and Materials from the Oceans and Aquatic Sources (eds Kerton, F. M. \& Yan, N.) 19-41 (Wiley, New York, 2017).

12. Zhao, X., Tang, X., Zhang, H., Qu, T. \& Wang, Y. Photosynthetic adaptation strategy of Ulva prolifera floating on the sea surface to environmental changes. Plant Physiol. Biochem. 107, 116-125 (2016).

13. Wichard, T. et al. The green seaweed Ulva: a model system to study morphogenesis. Front. Plant Sci. 6, 72 (2015).

14. Hurd, C. L., Harrison, P. J., Bischof, K. \& Lobban, C. S. Seaweed Ecology and Physiology 2nd edn. (Cambridge University Press, Cambridge, 2014).

15. Larsson, C., Axelsson, L., Larsson, C., Ryberg, H. \& Beer, S. Photosynthetic carbon utilization by Enteromorpha intestinalis (chlorophyta) from a swedish rockpool. Eur. J. Phycol. 32, 49-54 (1997).

16. Beer, S. \& Israel, A. Photosynthesis of Ulva sp.: III. $\mathrm{O}_{2}$ effects, carboxylase activities, and the $\mathrm{CO}_{2}$ incorporation pattern. Plant Physiol. 81, 937-938 (1986).

17. Beer, S., Israel, A., Drechsler, Z. \& Cohen, Y. Photosynthesis in Ulva fasciata: V. Evidence for an inorganic carbon concentrating system, and ribulose-1,5-bisphosphate carboxylase/oxygenase $\mathrm{CO}_{2}$ kinetics. Plant Physiol. 94, 1542-1546 (1990).

18. Drechsler, Z. \& Beer, S. Utilization of inorganic carbon by Ulva lactuca. Plant Physiol. 97, 1439-1444 (1991).

19. Xu, J. et al. Evidence of coexistence of $\mathrm{C}_{3}$ and $\mathrm{C}_{4}$ photosynthetic pathways in a green-tide-forming alga, Ulva prolifera. PLoS ONE 7, e37484 (2012).

20. Zheng, Z., Gao, S. \& Wang, G. High salt stress in the upper part of floating mats of Ulva prolifera, a species that causes green tides, enhances non-photochemical quenching. J. Phycol. 55, 1041-1049 (2019).

21. Zhang, X. et al. Roles of the transthylakoid proton gradient and xanthophyll cycle in the non-photochemical quenching of the green alga Ulva linza. Estuar. Coast. Shelf Sci. 163, 69-74 (2015).

22. Robic, A., Rondeau-Mouro, C., Sassi, J. F., Lerat, Y. \& Lahaye, M. Structure and interactions of ulvan in the cell wall of the marine green algae Ulva rotundata (Ulvales, Chlorophyceae). Carbohydr. Polym. 77, 206-216 (2009).

23. Lahaye, M. \& Robic, A. Structure and function properties of Ulvan, a polysaccharide from green seaweeds. Biomacromol 8, 1765-1774 (2007).

24. Kidgell, J. T., Magnusson, M., de Nys, R. \& Glasson, C. R. K. Ulvan: A systematic review of extraction, composition and function. Algal Res. 39, 101422 (2019).

25. Percival, E. \& Smestad, B. Photosynthetic studies on Ulva lactuca. Phytochemistry 11, 1967-1972 (1972).

26. Dersch, L. M. et al. Novel approach for high-through out metabolic screening of whole plants by stable isotopes. Plant Physiol. 171, 25-41 (2016).

27. Thomas, F., Duff, N. L., Leroux, C., Dartevelle, L. \& Riera, P. Isotopic labeling of cultured macroalgae and isolation of ${ }^{13}$ C-labeled cell wall polysaccharides for trophic investigations. Adv. Bot. Res. 95, 1-17 (2020).

28. Doppler, M. et al. Stable isotope-assisted plant metabolomics: Combination of global and tracer-based labeling for enhanced untargeted profiling and compound annotation. Front. Plant Sci. 10, 1366 (2019).

29. Weber, R., Selander, E., Sommer, U. \& Viant, M. A stable-isotope mass spectrometry-based metabolic footprinting approach to analyze exudates from phytoplankton. Mar. Drugs 11, 4158-4175 (2013).

30. Algal Culturing Techniques-1st Edition. https://www.elsevier.com/books/algal-culturing-techniques/andersen/978-0-12-08842 6-1. (Accessed 15 Aug 2020).

31. Harrison, P. J., Waters, R. E. \& Taylor, F. J. R. A broad spectrum artificial sea water medium for coastal and open ocean phytoplankton. J. Phycol. 16, 28-35 (1980).

32. Berges, J. A., Franklin, D. J. \& Harrison, P. J. Evolution of an artificial seawater medium: improvements in enriched seawater, artificial water over the last two decades. J. Phycol. 37, 1138-1145 (2001).

33. Littler, M. M. \& Arnold, K. E. Primary productivity of marine macroalgal functional-form groups from southwestern North America. J. Phycol. 18, 307-311 (1982).

34. Räbinä, J. et al. Analysis of nucleotide sugars from cell lysates by ion-pair solid-phase extraction and reversed-phase high-performance liquid chromatography. Glycoconj. J. 18, 799-805 (2001).

35. Ferrari, B. et al. Direct identification and quantitative determination of costunolide and dehydrocostuslactone in the fixed oil of Laurus novocanariensis by ${ }^{13} \mathrm{C}-\mathrm{NMR}$ spectroscopy. Phytochem. Anal. 16, 104-107 (2005). 
36. Otte, D. A. L., Borchmann, D. E., Lin, C., Weck, M. \& Woerpel, K. A. ${ }^{13}$ C NMR spectroscopy for the quantitative determination of compound ratios and polymer end groups. Org. Lett. 16, 1566-1569 (2014).

37. Kuwano, K., Sakurai, R., Motozu, Y., Kitade, Y. \& Saga, N. Diurnal cell division regulated by gating the G1/S transition in Enteromorpha compressa (Chlorophyta). J. Phycol. 44, 364-373 (2008).

38. Mc Arthur, D. M. \& Moss, B. L. The ultrastructure of cell walls in Enteromorpha intestinalis (L.) Link. Br. Phycol. J. 12, 359-368 (1977).

\section{Acknowledgements}

This work was supported in part by the research grant for Exploratory Research on Sustainable Humanosphere Science, Kyoto University and the Analysis and Development System for Advanced Materials (ADAM) from the Research Institute for Sustainable Humanosphere (RISH), Kyoto University, JST Matching Planner Program (MP28116808541), JSPS Grant-in-Aid for Young Scientists B (15K18814), Grant-in-aid for Exploratory Research (15K14224), Grant-in-Aid for Young Scientists A (17H05049), and Kochi University research project of the Biomass Refinery of Marine Algae and the Wood and Cabinet Office grant in aid, the Advanced NextGeneration Greenhouse Horticulture by IoP (Internet of Plants), Japan. The authors are grateful to Dr. Minoru Ikehara, Kiriyo Oono, and Yutaro Kinoshita at Kochi Univ. for their support in CHNS analysis, compositional analysis, and algae cultivation.

\section{Author contributions}

S.T. and M.H. designed experiments. S.T. and M.H. performed ${ }^{13} \mathrm{C}$ labelling cultivation. S.T., A.O., H.N., and T.I. performed FT-ICR-MS, ${ }^{13} \mathrm{C}-\mathrm{NMR}$, and GC-MS analysis. S.T. wrote the manuscript.

\section{Competing interests}

The authors declare no competing interests.

\section{Additional information}

Supplementary information is available for this paper at https://doi.org/10.1038/s41598-020-77237-1.

Correspondence and requests for materials should be addressed to S.T.

Reprints and permissions information is available at www.nature.com/reprints.

Publisher's note Springer Nature remains neutral with regard to jurisdictional claims in published maps and institutional affiliations.

(c) (i) Open Access This article is licensed under a Creative Commons Attribution 4.0 International License, which permits use, sharing, adaptation, distribution and reproduction in any medium or format, as long as you give appropriate credit to the original author(s) and the source, provide a link to the Creative Commons licence, and indicate if changes were made. The images or other third party material in this article are included in the article's Creative Commons licence, unless indicated otherwise in a credit line to the material. If material is not included in the article's Creative Commons licence and your intended use is not permitted by statutory regulation or exceeds the permitted use, you will need to obtain permission directly from the copyright holder. To view a copy of this licence, visit http://creativecommons.org/licenses/by/4.0/.

(c) The Author(s) 2020 